\title{
Study of the parameter affecting the adsorption of substiuted phenols by activated carbon which prepared by chemical treatment
}

\author{
Safwan A. Al-Dbone \\ Department of Chemistry / College of Education \\ University of Mosul
}

Received

14 / 06 / 2011
Accepted

$05 / 10 / 2011$

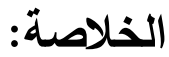

تضمن البحث دراسة امتزاز عدد من معوضات الفينول على نوع جديد من الكاربون المنشط

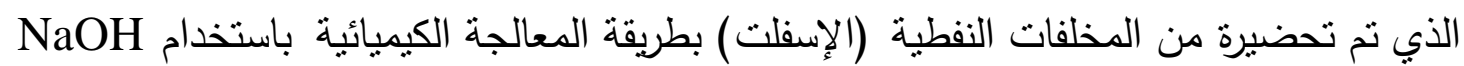

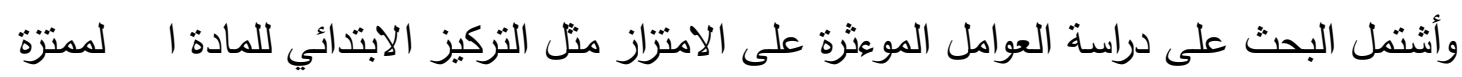

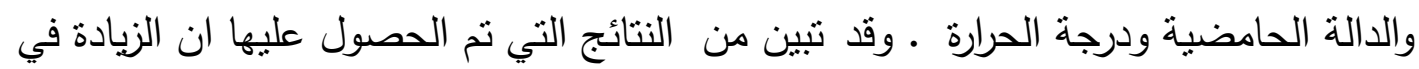

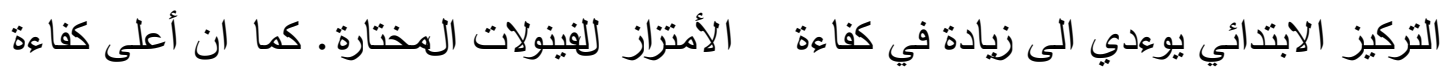

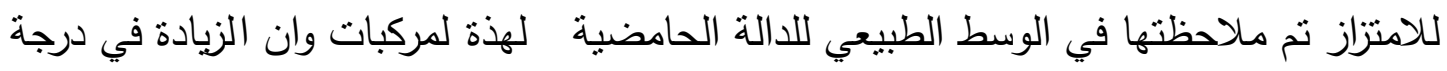
الحرارة توعدي الى نقصان في كمية الفينولات الممتزة مشيرة الى الطبيعة الفيزيائية للامتزاز للنظام. وبالاعتماد على النتائج التي ثم الحصول علئ عليها من تأثثر درجة الحرارة ونم حساب الدوال

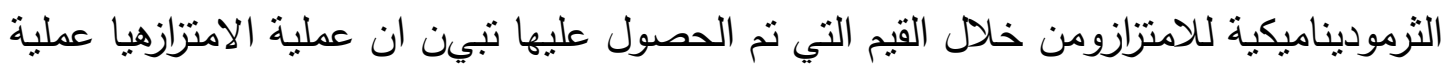
تلقائية وباعثة الحرارة ومسيطر عليها بأثفير الانتروبي. وقداعطى تطبيق ايزوثيرم فرندلخ البيانات العملية للامتزاز أنطباق جيد للنظام قيد الدئيد الدراسة.

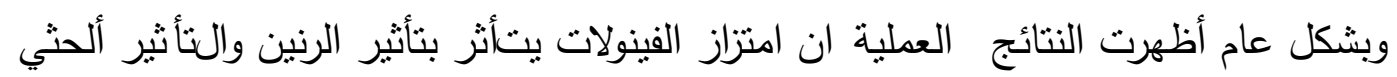

الذي تحدثه المعوضات على المركبات المعتدة.

\begin{abstract}
In this research, the adsorption of substituted phenols on anewly synthesized a activated carbons has been investigated. The activated carbon is prepared from spent petroleum materials (Asphalt) and chemically activated by employing $\mathrm{NaOH}$.

The work included studying the factors affecting the adsorption process such as initial concentration, $\mathrm{pH}$ and temperature. The results
\end{abstract}


indicated that, the increase of initial concentration increases the efficiency of adsorbed phenols. The highest adsorption efficiency is observed in the neutral medium of the studied compound. Increasing the temperature decreases the amount of adsorbed phenols suggesting the physical nature of adsorption system under consideration.

Depending on the effect of temperature, the thermodynamic functions of adsorption were estimated. The obtained values showed that, the adsorption process is spontaneous, exothermic and controlled by entropy effect.

The application of Freundlich isotherm is good Fitted the experimental data of the adsorption system.

The overall results showed that, the adsorption of the investigated compounds are affected by the resonance and inductive effect of the concerned subsistent.

\section{Introduction}

Adsorption is the retention of molecules onto the surface of an active solid due to certain physical and chemical attractive forces. The aim of using activated solid (such as activated carbon) is to produce a material of high surface area per unit volume with high porosity ${ }^{(1)}$.

The study of adsorption is important for various physico-chemical processes and for understanding phenomena such as clarification and depolution of industrial liquid effluents ${ }^{(2,3)}$.

Adsorption applications have expanded rapidly because of the sharp rising of environmental and quality requirement. The development of adsorbent technology have made it possible to meet many of those demands $^{(4)}$.

Adsorptions is often used as a method for treating aqueous solution to remove dissolved contaminating organic compounds.

Organic are of a great concern is water treatment since most of them are often carcinogenic, highly toxic and undesirable ${ }^{(5)}$

The most conventional adsorption system being activated carbon. Adsorption by activated carbon is proved to be a desirable technology to remove dissolved organics from wastewater flows that contains a significant quantities of industrial waste ${ }^{(6)}$.

The reason for the use of activated carbon in the removal of dissolved substances from water by adsorption process adsorbent due to its large number of pores which provide a large surface area compared to the size of the actual carbon particle and its visible exterior surface ${ }^{(7)}$.

Adsorption is affected by temperature and concentration. The variation of the extent of adsorption with concentration is given by empirical isotherms, which are used to predict the amount of adsorbed material at definite temperature. Freundlich and Langmuir are two of the most known isotherms among many other reported in the literature ${ }^{(4)}$. 
Nouri et.al ${ }^{(8)}$, studied the adsorption of three types of aromatic hydrocarbons having different functional groups onto untreated carbon. The study involved effect of $\mathrm{pH}$ and concentration on the nature of adsorption. It showed that, the maximum adsorption is varied according to the size and nature of functional group, on the other hand, the adsorption on such carbon was found to be heterogeneous to a certain extent.

Fariba ${ }^{(9)}$ studied the adsorption of phenols on certain type of a sandy material. The main tasks were to establish quantitative relationships describing the overall sorption of various substituted phenols at different $\mathrm{pH}$, and to estimate the adsorption coefficient of neutral and ionic forms on adsorbent used.

Interest in the environmental behavior of dyes is prompted primarily by concern over their possible toxicity and carcinogenicity heightened by the fact that many of the dyes are synthezied from strating materials which their and toxicity and long term effects on animal and human health are well known. A great efforts have been concentrated on the treatment of such material, in the industrial wastewater ${ }^{(10)}$.

Albanis et al., studied the removal of five commercial dyes from aqueous suspensions on a sandy clay soil of low organic materials content. The experiments were carried out at equilibrium conditions in a concentration range of 5- $60 \mathrm{mg} \mathrm{l}^{-1}$. The fitting of the experimental data of the adsorption to Freundlich isotherm gave linear relation. The removal of these dyes from solution were highly dependent on concentration.

In an other study ${ }^{(11)}$, the decolorization of prepared aqueous solutions of three reactive azo dyes used in textile processing by adsorption on different types of powdered activated carbon were investigated, and the coulour removal efficiency and equilibrium adsorption isotherms for these dyes were estimated using five commercial powdered activated carbon.

Favere et al., ${ }^{(12)}$ studied the adsorption of some anionic dyes on a certain type of polymer, employing the Langmuir isotherm. The results showed that the adsorption capacity is dependent of $\mathrm{pH}$. The adsorption was dominated by Van der Walls forces and hydrogen bonding. The study showed that the temperature increase reduces the adsorption capacity and the value $\left(<40 \mathrm{KJ}\right.$. mole $\left.{ }^{-1}\right)$ proved the physical nature of the adsorption by these dyes.

In a recently published paper ${ }^{(13)}$, the authors investigated the adsorption of aromatic carboxyl acids carrying various substituents such as $\mathrm{OH}, \mathrm{NH} 2$, and $\mathrm{SH}$. The effect of concentration, temperature and $\mathrm{pH}$ were studied and the thermodynamic function $\left(\Delta G^{\circ}, \Delta S^{\circ}, \Delta H\right)$ of the adsorption at equilibrium were calculated. The results revealed that the 
hydrogen bond present in the systems in addition to other attraction forces have great effect on the adsorption.

The aim of this work is to study the removal of phenol and some of its substituted phenol from their aqueous solution, by using a new type of substituted activated carbon.

\section{Experimental}

The adsorption prosses of considered compounds from their aqueous solutions were achieved as batch method, and by employing single component solution of the phenolic compounds of interest. A range of concentrations of each studied compounds were used for achieving this investigation.

The amount of the remained compounds in the solution (free phenols) were determined by the titration with a standarized $\mathrm{NaOH}$ solution. The amount of adsorbed phenols were estimated by difference. Various effects were studied as parameters affecting the adsorption process.

\section{Instruments}

Programable water bath and shecker type (Julabo/Sw23/Germany) and $\mathrm{pH}$ meter type (2100/Oakon/Germany) are used for achieving two study.

\section{Preparation of stock solution for phenol and substituted phenols}

Exact weight of prepurified phenol was dissolved in water using 100 $\mathrm{ml}$ volumetric Flask. Few drops of ethanol was added to the solution for ensuring complete solubility. The prepared sample was kept in a reagent botle for Further study.

\section{Adsorption of phenols from the aqueous medi:}

Exact weight of activated carbon $(0.01 \mathrm{gm})$ was transferred to a conical flask containing previously $5 \mathrm{ml}$ and 10, 15, 20 and $25 \mathrm{ml}$ of the stock solution were added to the same amount of activated carbon. The series under study was shacked at constant temperature for $1 \mathrm{hr}$. After the time past the samples were filtered and used for the determination of the residual phenols. The adsorption of the same phenol was carried out at various temperaturs, different $\mathrm{pH}$ and different concentrations.

\section{Determination of the remained unadsorbed phenols:}

First; the concentrations of all the stock solution were determined by titration with standardized sodium hydroxide solution $(0.1 \mathrm{M})$ using ph.ph as indicater The fillerate from step 2 was used for the determination of remaining phenol. 


\section{Determination of optimal conditions:}

The determination each parameter such as concentration, temperature constant and different $\mathrm{pH}$ and different functional group type and position were investigated.

\section{Adsorbent}

Adsorbent selected for this study is an activated carbon, synthesized in our laboralony. From a spent petrotium material by employing condensed oxidation method. The carbon was chemically activated using $\mathrm{NaOH}$.

The resulted carbon is characterized by its density $\left(0.31 \mathrm{~g} . \mathrm{cm}^{-3}\right)$, ash content ratio $(1.321 \%)$ humidity content ratio $(1.521 \%)$ and adsorption capacity of iodine (950 mg.g $\left.{ }^{-1}\right)$ and the methylene blue dye $\left(149 \mathrm{mg} \cdot \mathrm{g}^{-1}\right){ }^{(14)}$

\section{Result and discussion}

\section{Effect of initial concentration}

The effect of initial concentration is conducted at equilibrium conditions within the range of $\left(2.5 \times 10^{-2}-1.25 \times 10^{-1} \mathrm{~mol} / \mathrm{L}\right)$ while keeping all the other parameters constant. The results obtained are listed in Table (1). The adsorption efficiencies are calculated in terms of the percentage of the adsorbed phenol (eq..1) and the equilibrium constant (eq...2)

$\%$ adsorption $=\frac{C i-C e}{C i} \times 100$.

$\mathrm{K}_{\mathrm{ad}}=\frac{C i-C e}{C e}$.

Where $\mathrm{Ci}$ and $\mathrm{Ce}$ are the initial and remained concentrations of the tested compound respectively, $(\mathrm{Ci}-\mathrm{Ce})$ is the amount of adsorbed phenol.

Table (1): The effect of concentration on adsorption of studied compounds at

\begin{tabular}{|c|c|c|c|}
\hline Comp. & $\begin{array}{l}\text { Conc. } \\
\text { (mol/li) }\end{array}$ & $\mathbf{K}$. & \%Ads. \\
\hline $\mathrm{Ph}$ & $\begin{array}{l}r .0 \times 10^{-r} \\
0 \times 10^{-r} \\
r .0 \times 10^{-r} \\
\left(\times 10^{-1}\right. \\
1 . r \otimes \times 1 \cdot 0^{-1}\end{array}$ & $\begin{array}{l}10.4 \\
18.9 \\
17.1 \\
r .4 \\
r 0.1\end{array}$ & $\begin{array}{l}43.7 \\
46.8 \\
47.3 \\
50.1 \\
52.3\end{array}$ \\
\hline o-CH3-Ph & $\begin{array}{l}r .0 \times 10^{-r} \\
0 \times 10^{-r} \\
v .0 \times 10^{-r} \\
\mid \times 10^{-1} \\
1 . r \circ \times 10^{-1}\end{array}$ & $\begin{array}{l}9.1 \\
1 \leq .7 \\
19.7 \\
17.0 \\
47.9\end{array}$ & $\begin{array}{l}41.6 \\
42.8 \\
46.1 \\
47.8 \\
48.1\end{array}$ \\
\hline
\end{tabular}


Study of the parameter affecting the adsorption of substiuted phenols by ...

\begin{tabular}{|c|c|c|c|}
\hline Comp. & $\begin{array}{l}\text { Conc. } \\
\text { (mol/li) }\end{array}$ & K. & \%Ads. \\
\hline $\begin{array}{r}\mathrm{CH}_{3} \\
\mathrm{~m}-\mathrm{CH} 3-\mathrm{Ph}\end{array}$ & $\begin{array}{l}r .0 \times 10^{r-r} \\
0 \times 10^{-r} \\
v .0 \times 10^{-r} \\
\left(\times 10^{-1}\right. \\
1 . r 0 \times 10^{-1}\end{array}$ & $\begin{array}{l}13.7 \\
18.0 \\
19.5 \\
20.5 \\
23.5\end{array}$ & $\begin{array}{l}43.6 \\
44.7 \\
45.3 \\
46.8 \\
50.1\end{array}$ \\
\hline $\begin{array}{c}\mathrm{CH}_{3} \\
\text { p-CH3-Ph }\end{array}$ & $\begin{array}{l}r .0 \times 10^{r} \\
0 \times 10^{r} \\
r .0 \times 10^{-r} \\
\mid \times 10^{-1} \\
1 . r \circ \times 1 .^{-1}\end{array}$ & $\begin{array}{c}22.0 \\
33.0 \\
54.0 \\
83.1 \\
210.3\end{array}$ & $\begin{array}{l}46.1 \\
49.3 \\
50.4 \\
52.6 \\
57.3\end{array}$ \\
\hline$-\mathrm{Ph}$ & $\begin{array}{l}r .0 \times 10^{-r} \\
0 \times 10^{-r} \\
r .0 \times 10^{-r} \\
\mid \times 10^{-1} \\
1 . r 0 \times 1 .^{-1}\end{array}$ & $\begin{array}{l}24.0 \\
33.0 \\
37.6 \\
40.8 \\
42.8\end{array}$ & $\begin{array}{l}45.8 \\
47.2 \\
50.4 \\
52.3 \\
56.4\end{array}$ \\
\hline $\begin{array}{l}\mathrm{NH}_{2} \\
\mathrm{~m}-\mathrm{NH} 2-\mathrm{Ph}\end{array}$ & $\begin{array}{l}r .0 \times 10^{-r} \\
0 \times 10^{-r} \\
v .0 \times 10^{-r} \\
i \times 10^{-1} \\
1 . r 0 \times 1 .^{-1}\end{array}$ & $\begin{array}{c}23.2 \\
28.0 \\
54.0 \\
78.5 \\
108.0\end{array}$ & $\begin{array}{l}46.3 \\
48.6 \\
50.4 \\
54.1 \\
58.3\end{array}$ \\
\hline $\begin{array}{c}\mathrm{NH}_{2} \\
\text { p-NH2 }-\mathrm{Ph}\end{array}$ & $\begin{array}{l}r .0 \times 10^{-r} \\
0 \times 1 .^{-r} \\
v .0 \times 10^{-r} \\
\mid \times 10^{-1} \\
1 . r 0 \times 1 .^{-1}\end{array}$ & $\begin{array}{c}53.5 \\
144.5 \\
322.0 \\
837.4 \\
1599.0\end{array}$ & $\begin{array}{l}50.3 \\
51.2 \\
50.9 \\
50.6 \\
56.8\end{array}$ \\
\hline o-NO2 -Ph & $\begin{array}{l}r .0 \times 10^{-r} \\
0 \times 10^{-r} \\
r .0 \times 10^{-r} \\
\mid \times 10^{-1} \\
1 . r 0 \times 1 .^{-1}\end{array}$ & $\begin{array}{c}23.5 \\
54.0 \\
325.0 \\
822.0 \\
15811.7\end{array}$ & $\begin{array}{l}50.1 \\
52.3 \\
54.6 \\
50.4 \\
59.4\end{array}$ \\
\hline${ }_{\mathrm{o}-\mathrm{CO} 2 \mathrm{H}-\mathrm{Ph}}$ & $\begin{array}{l}r .0 \times 10^{-r} \\
0 \times 10^{-r} \\
v .0 \times 1 .^{-r} \\
\left(\times 10^{-1}\right. \\
1 . r 0 \times 1 .^{-1}\end{array}$ & $\begin{array}{c}22.0 \\
34.5 \\
38.0 \\
79.0 \\
228.0\end{array}$ & $\begin{array}{l}55.3 \\
57.8 \\
60.3 \\
61.2 \\
63.4\end{array}$ \\
\hline
\end{tabular}

The results of Table (1) shows that the increase of initial concentration increases the ratio of adsorbed phenols. Comparison between the adsorption efficiencies of the $\mathrm{o}, \mathrm{m}$, and $\mathrm{p}$-phenol compounds shows that, the adsorption efficiency is clearly affected by steric and inductive effects:

$\mathrm{o}-\mathrm{CH}_{3}-\mathrm{ph}<\mathrm{m}-\mathrm{CH}_{3}$ ph $<\mathrm{p}-\mathrm{CH} 3-\mathrm{ph}$

$\mathrm{O}-\mathrm{NH}_{2}-\mathrm{Ph}-\mathrm{m}-\mathrm{NH}_{2}-\mathrm{ph}<\mathrm{p}-\mathrm{NH}_{2}-\mathrm{ph}$ 
The effect of hydrogen bonding (inter and intra) is clearly observed in the overall results.

\section{Effect of Temperature}

The adsorption efficiency is estimated at various temperatures in the range of $(15-40): \mathrm{C}$. The experiments were performed while keeping all other parameters constant. The initial concentration was $\left(1.25 \times 10^{-1}\right)$ and $\mathrm{pH}$ medium of the phenolic solution was the natural $\mathrm{pH}$ of each of them The results obtained are shown in Table (2).

Table(2): Effect of Temperature on the adsorption efficiency of phenols

\begin{tabular}{|c|c|c|c|c|c||}
\hline Comp. & $\mathbf{1 5 C}^{\circ}$ & $\mathbf{2 0 C}^{\circ}$ & $\mathbf{2 5 C}^{\circ}$ & 30C $^{\circ}$ & $\mathbf{4 0 C}^{\circ}$ \\
\hline $\mathrm{Ph}$ & 52.3 & 49.8 & 46.3 & 43.6 & 39.4 \\
\hline $\mathrm{o}-\mathrm{CH}_{3}-\mathrm{Ph}$ & 48.1 & 45.2 & 41.8 & 38.7 & 35.4 \\
\hline $\mathrm{m}-\mathrm{CH}_{3}-\mathrm{Ph}$ & 50.1 & 47.5 & 46.3 & 42.1 & 38.6 \\
\hline $\mathrm{p}-\mathrm{CH}_{3}-\mathrm{Ph}$ & 57.3 & 54.6 & 52.1 & 49.3 & 42.6 \\
\hline $\mathrm{o}-\mathrm{NH}_{2}-\mathrm{Ph}$ & 56.4 & 53.2 & 50.9 & 47.3 & 41.6 \\
\hline $\mathrm{m}-\mathrm{NH}_{2}-\mathrm{Ph}$ & 58.3 & 54.7 & 52.1 & 48.3 & 42.7 \\
\hline $\mathrm{p}-\mathrm{NH}_{2}-\mathrm{Ph}$ & 56.8 & 52.4 & 50.9 & 46.2 & 41.3 \\
\hline $2-\mathrm{Ph} \mathrm{o}-\mathrm{NO}$ & 59.4 & 54.7 & 52.1 & 48.3 & 42.6 \\
\hline $\mathrm{o}-\mathrm{CO}_{2} \mathrm{H}-\mathrm{Ph}$ & 63.4 & 58.6 & 52.4 & 48.2 & 42.1 \\
\hline
\end{tabular}

The results of Table (2) indicated that the amount of adsorbed phenolic compounds decreased with increasing temperature. A similar patren was noticed for all of them.

This observation suggests that, the adsorption process of the studied systems are exothermic and physical in nature. The increase of temperature increased the desorption process.

\section{Effect of pH}

The effect of varying $\mathrm{pH}$ of phenolic compounds solution prior to adsorption while maintaining all other factors constants is investigated at three different $\mathrm{pH}$ media, acidic $(\mathrm{pH}=4)$ neutral $\mathrm{pH}=7$, and basic $\mathrm{pH}=9$, in addition to the natural $\mathrm{pH}$. solution of the selected compounds for this study.

Table (3): Effect of varying pH on the adsorption efficiency of phenols

\begin{tabular}{|c|c|c|c|c|}
\hline Compd. & $\begin{array}{c}\mathbf{p H} \\
\text { Natural }\end{array}$ & pH7 & pH4 & pH9 \\
\hline $\mathbf{P h}$ & $52.3(6.8)$ & 50.1 & $48 . .5$ & 36.2 \\
\hline o-CH3-Ph & 48.1(6.1) & 46.8 & 43.5 & 34.7 \\
\hline m-CH3-Ph & 50.1(6.2) & 49.3 & 45.8 & 36.9 \\
\hline p-CH3-Ph & 57.3(6.8) & 55.2 & 51.6 & 41.3 \\
\hline o-NH2 - Ph & 56.4(7.3) & 56.0 & 50.9 & 44.8 \\
\hline m-NH2 -Ph & 58.3(7.2) & 57.8 & 52.7 & 42.1 \\
\hline p-NH2 -Ph & 56.8(7.1) & 56.5 & 50.4 & 46.9 \\
\hline o-NO2 -Ph & 59.4(7.0) & 59.4 & 52.8 & 41.6 \\
\hline o-CO2H -Ph & 63.4(7.5) & 61.4 & 56.7 & 42.4 \\
\hline
\end{tabular}


The results of Table (3), in dicated that, the amount of adsorbed phenols is higher at the neutral medium (close to the natural $\mathrm{pH}$ of the studied compounds) and decrease at the acidic and basic medium this result leads to that, the phenolic compounds is attached to the activated carbon under consideration in their - neutral forms through hydrogenbonding or similar forces. The phenolic compounds may be ionized in the aqueous solution as in the equation in the acidic medium

$p h-o H \rightarrow p h o^{-}+H^{+}$

Where as they present as a salt (sodium pheoxide) in the basic medium. In both of these media the adsorption process is deactivated.

\section{Thermodynamic Calculations}

The calculation of thermodynamic parameters of adsorption represent a good measure for the direction of the process, the nature of the forces control it and order of the adsorption system, which occurs as a result of various intermolecular forces between the adsorbate and adsorbent surface.

The estimation of heat of adsorption is conducted depending on the adsorption isotherm knowledge at various temperatures.

The value of adsorption equilibrium constant $(\mathrm{Kd})$ are determined at different temperatures from the ratio between the adsorbed and free phenols concentration at equilibrium, using the following equation.

$K d=\frac{C a d s}{C e}$

Where Cads and Ce are the concentrations of the adsorbed and remained phenols at equilibrium respectively.

The value of $\Delta \mathrm{H}$ is estimated from the application of vant Hoff's equation.

$$
\text { lnk }=\frac{-\Delta H}{R T}+\text { cons } \tan t
$$

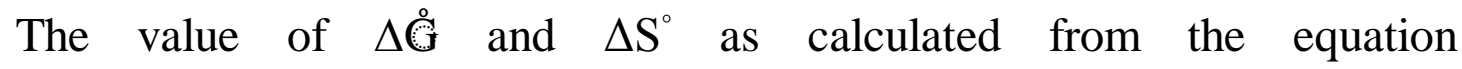
resepectively.

$$
\begin{aligned}
& \Delta \mathrm{G}^{\circ}=-\mathrm{RT} \ln \mathrm{k} \\
& \Delta \mathrm{G}^{\circ}=\Delta \mathrm{H}-\mathrm{T} \Delta \mathrm{S}^{\circ}
\end{aligned}
$$

Where $\mathrm{R}$ is the gas constant $\left(8.314 \mathrm{~J} \cdot \mathrm{mol}^{-1} \cdot \mathrm{K}^{-1}\right)$ and $\mathrm{T}$ is the absolute temperature. The thermodynamic parameters listed in table (4)

Straight lines are obtained from plotting $\ln \mathrm{K}$ versus $1 / \mathrm{T}$ (shown in Figures 1-4). 


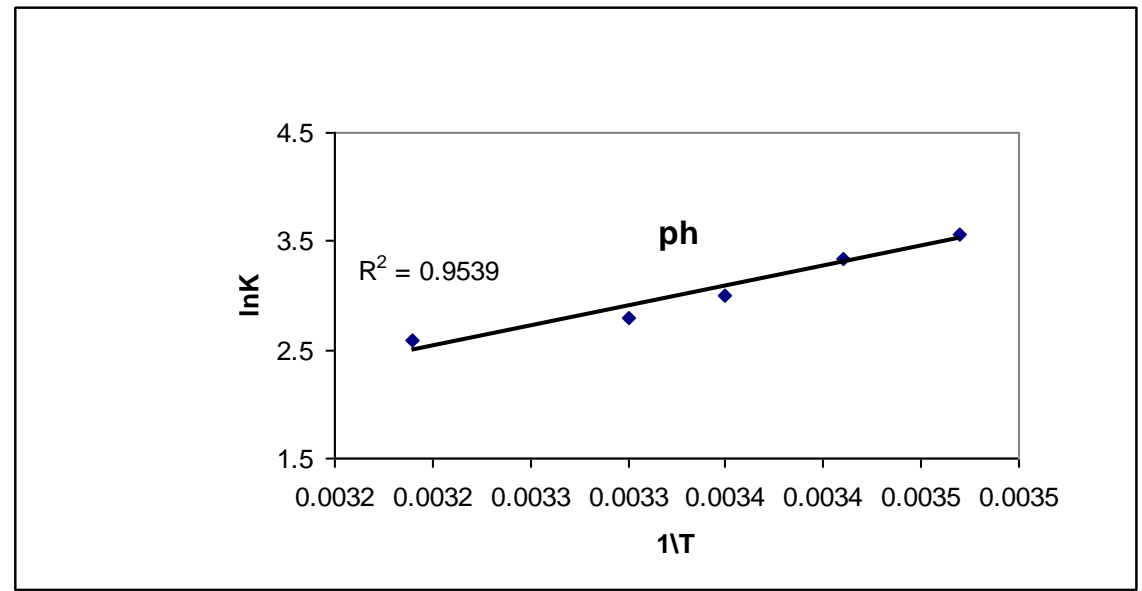

Fig 1: Relation between $\ln k$ and 1/T for phenol.

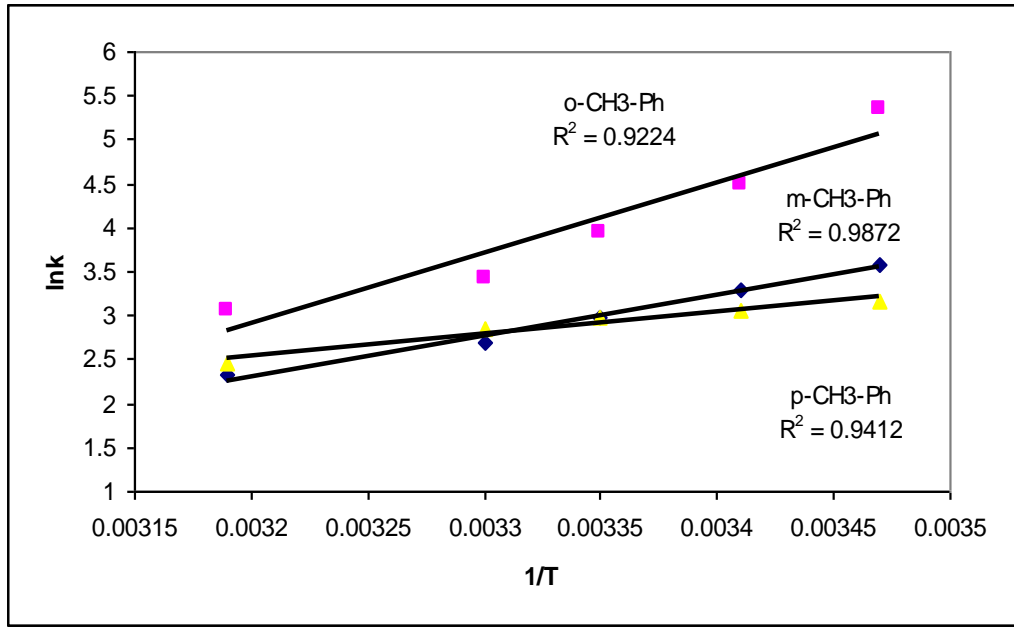

Fig 2: Relation between $\ln \mathrm{k}$ and 1/T for ortho,meta and Para methyl phenol.

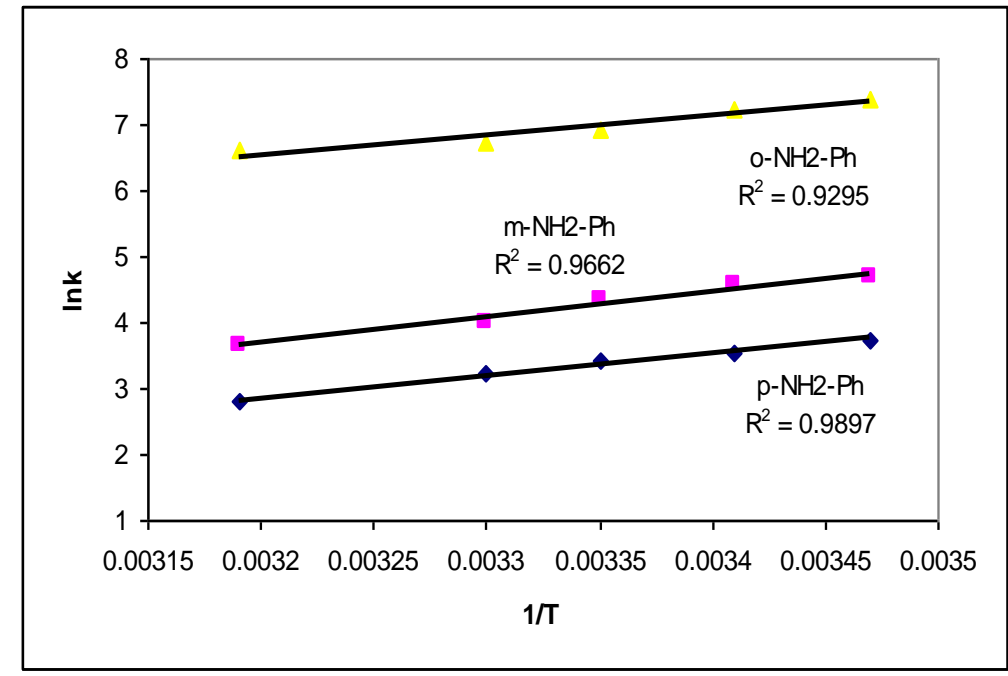

Fig 3: Relation between $\ln k$ and 1/T for ortho,meta and Para amino phenol. 
Study of the parameter affecting the adsorption of substiuted phenols by ...

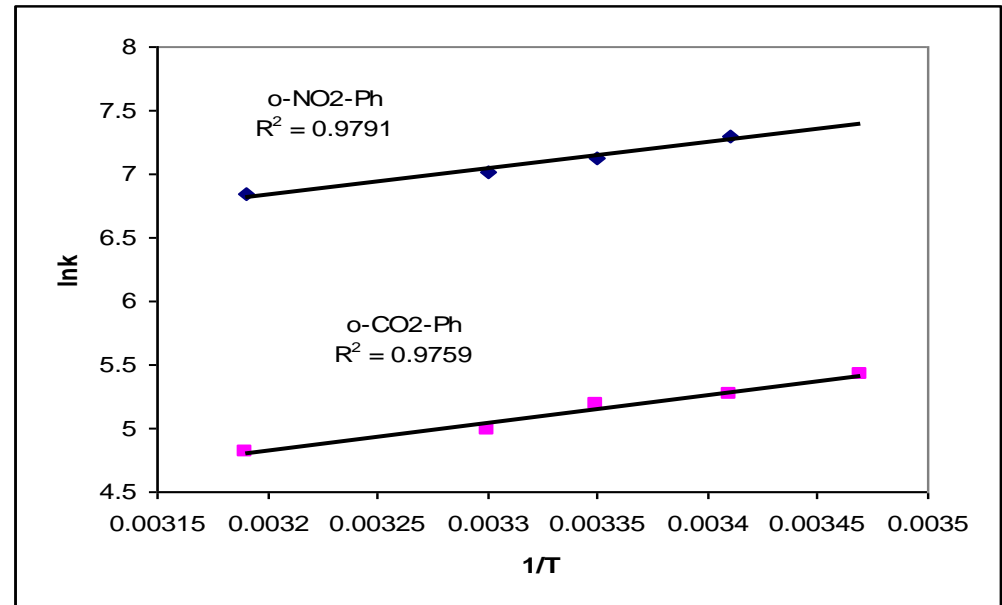

Fig 4: Relation between $\ln k$ and $1 / T$ for ortho nitro phenol and ortho carboxyl phenol

The values of $\mathrm{K}$ and other thermodynamic parameters are listed in Table(4).

Table(4): the values of the equilibrium constant and the thermodynamic parameters of the adsorption of phenols

\begin{tabular}{|c|c|c|c|c|c|}
\hline Comp. & Tk & $\mathbf{K}$ & \begin{tabular}{c}
\multicolumn{1}{c}{$\Delta \mathrm{G}^{\circ}$} \\
KJ.mol $^{-1}$
\end{tabular} & $\begin{array}{c}\Delta S^{\circ} \\
\mathbf{J} \cdot \mathrm{mol}^{-1} \cdot \mathbf{k}^{-1}\end{array}$ & $\begin{array}{c}\Delta H^{-1} \\
\text { J.mol }^{-1}\end{array}$ \\
\hline \multirow{5}{*}{$\mathbf{P h}$} & 288 & 35.5 & -8.54 & 28.16 & \multirow{5}{*}{-435.37} \\
\hline & 293 & 28.4 & -8.14 & 26.32 & \\
\hline & 298 & 20.1 & -7.43 & 23.47 & \\
\hline & 303 & 16.5 & -7.05 & 21.83 & \\
\hline & 313 & 13.4 & -6.73 & 20.13 & \\
\hline \multirow{5}{*}{ o-CH3-Ph } & 288 & 36.0 & -8.57 & 27.84 & \multirow{5}{*}{-552.48} \\
\hline & 293 & 27.0 & -8.013 & 25.46 & \\
\hline & 298 & 19.8 & -7.38 & 22.91 & \\
\hline & 303 & 14.6 & -6.75 & 20.45 & \\
\hline & 313 & 10.2 & -6.03 & 17.52 & \\
\hline \multirow{5}{*}{ m-CH3-Ph } & 288 & 23.5 & -7.54 & 25.15 & \multirow{5}{*}{-297.59} \\
\hline & 293 & 21.4 & -7.45 & 24.42 & \\
\hline & 298 & 19.8 & -7.38 & -23.77 & \\
\hline & 303 & 17.5 & -7.20 & -22.80 & \\
\hline & 313 & 11.6 & -6.37 & -19.41 & \\
\hline \multirow{5}{*}{ p-CH3-Ph } & 288 & 210.3 & -12.7 & 41.02 & \multirow{5}{*}{-969.84} \\
\hline & 293 & 90.7 & -10.96 & 34.09 & \\
\hline & 298 & 51.6 & -9.76 & 29.49 & \\
\hline & 303 & 30.8 & -8.61 & 25.23 & \\
\hline & 313 & 21.6 & -7.98 & 22.42 & \\
\hline \multirow{5}{*}{ o-NH2 -Ph } & 288 & 42.8 & -8.97 & 29.75 & \multirow{5}{*}{-408.51} \\
\hline & 293 & 35.1 & -8.64 & 28.11 & \\
\hline & 298 & 30.6 & -8.47 & 27.05 & \\
\hline & 303 & 25.2 & -8.11 & 26.63 & \\
\hline & 313 & 16.4 & -7.25 & 21.88 & \\
\hline
\end{tabular}




\begin{tabular}{||c|c|c|c|c|c||}
\hline \hline & & & & & \\
\hline & 288 & 108.0 & -11.20 & 37.27 & \\
m-NH2 -Ph & 293 & 97.6 & -11.15 & 36.47 & \\
& 298 & 78.5 & -10.80 & 34.67 & -468.69 \\
& 303 & 54.2 & -10.05 & 31.62 & \\
& 313 & 39.1 & -9.52 & 28.92 & \\
\hline & 288 & 1599.0 & -17.64 & 60.04 & \\
p-NH2 -Ph & 293 & 1375.1 & -17.58 & 58.81 & \\
& 298 & 1018.3 & -17.14 & 56.34 & -352.54 \\
& 303 & 836.0 & -16.92 & 54.70 & \\
\hline & 313 & 735.8 & -17.17 & 53.73 & \\
\hline & 288 & 15811 & -23.12 & 76.85 & \\
& 293 & 1468.2 & -17.75 & 57.21 & \\
& 298 & 1257.0 & -17.66 & 55.93 & -993.57 \\
& 303 & 1117.3 & -17.65 & 54.99 & \\
& 313 & 938.6 & -17.79 & 53.68 & \\
\hline \multirow{3}{*}{ o-CO2H -Ph -Ph } & 288 & 228.0 & -12.97 & 44.14 & \\
& 293 & 193.6 & -12.81 & 42.83 & \\
& 298 & 178.2 & -12.83 & 42.18 & -261.33 \\
& 303 & 146.4 & -12.54 & 40.53 & \\
& 313 & 125.1 & -12.54 & 39.23 & \\
\hline
\end{tabular}

The results in Table (4) shows that, the adsorption processes of the studied system are exothermic (negative values of $\Delta \mathrm{H}$ ) and the forces responsible for the attachment of adsorbate with the carbon surface are weak and physical in nature.

The positive values of $\Delta S^{\circ}$ explained the decrease in order in the adsorption system which may be resulted from the increase of hydrogen ions in the solution due to the ionization process of the phenolic compounds as week acids. The adsorption process of the studied systems are clearly controlled by entropy effect. The negative values of $\Delta G^{\circ}$ indicate to the sponteniety of the process.

\section{Application of Freundlich isotherm}

The Freundlich isotherm is an empirical equation assuming that, the adsorption process takes place on heterogeneous surfaces and adsorption capacity is related to the concentration of phenolic compounds at equilibrium. The Freundlich isotherm can be expressed as follow: $\ln \mathrm{qe}=\ln \mathrm{KF}+1 / \mathrm{n} \operatorname{lnCe}$

Where qe/is the adsorption capacity at equilibrium (mg. $\left.\mathrm{g}^{-1}\right)$. Kf and $\mathrm{n}$ are Freundlich parameters related to the adsorption capacity and adsorption intensity respectively. The value of $\mathrm{n}$ is an indication of favorability of adsorption, value of $n>1$ represent favorable adsorption condition.

The values of $K_{f,} n$ and the linear regression correlation coefficient obtained from the application of Freundlich model on the experimental adsorption data of phenols onto activated carbon are given in Table (5). 
Study of the parameter affecting the adsorption of substiuted phenols by ...

Table (5): Results of the application of Freundlich isotherm on the adsorption data of phenols on carbon

\begin{tabular}{|c|c|c|c|}
\hline$\frac{\text { compd }}{\text { Ph }}$ & $\underline{\mathbf{n}}$ & $\underline{\mathbf{k f}}$ & $\underline{\mathbf{R}^{2}}$ \\
\hline o-CH3-Ph & 1.09 & $\mathbf{0 . 9 9 5}$ & $\mathbf{0 . 9 7 9}$ \\
\hline m-CH3-Ph & 1.08 & $\mathbf{0 . 9 8 5}$ & $\mathbf{0 . 9 6 3}$ \\
\hline p-CH3-Ph & 1.11 & $\mathbf{0 . 9 8 4}$ & $\mathbf{0 . 9 2 6}$ \\
\hline o-NH2 -Ph & 1.04 & $\mathbf{0 . 9 9 2}$ & $\mathbf{0 . 9 7 8}$ \\
\hline m-NH2 -Ph & 1.06 & $\mathbf{0 . 9 7 8}$ & $\mathbf{0 . 9 9 7}$ \\
\hline p-NH2 -Ph & 1.03 & $\mathbf{0 . 9 7 1}$ & $\mathbf{0 . 9 8 3}$ \\
\hline o-NO2 -Ph & 1.15 & $\mathbf{0 . 9 4 6}$ & $\mathbf{0 . 9 8 3}$ \\
\hline o-CO2H -Ph & 1.02 & $\mathbf{0 . 9 5 3}$ & $\mathbf{0 . 9 4 4}$ \\
\hline
\end{tabular}

The plot of $\ln$ qe versus $\ln$ Ce should give a straight line with correlation coefficient $\left(\mathrm{R}^{2}\right)$ close to unity if this isotherm to be applicable.

The result, of Table (5) indicate that, the Freundlich isotherm is good fit will the experimental data of adsorption of the considered system.
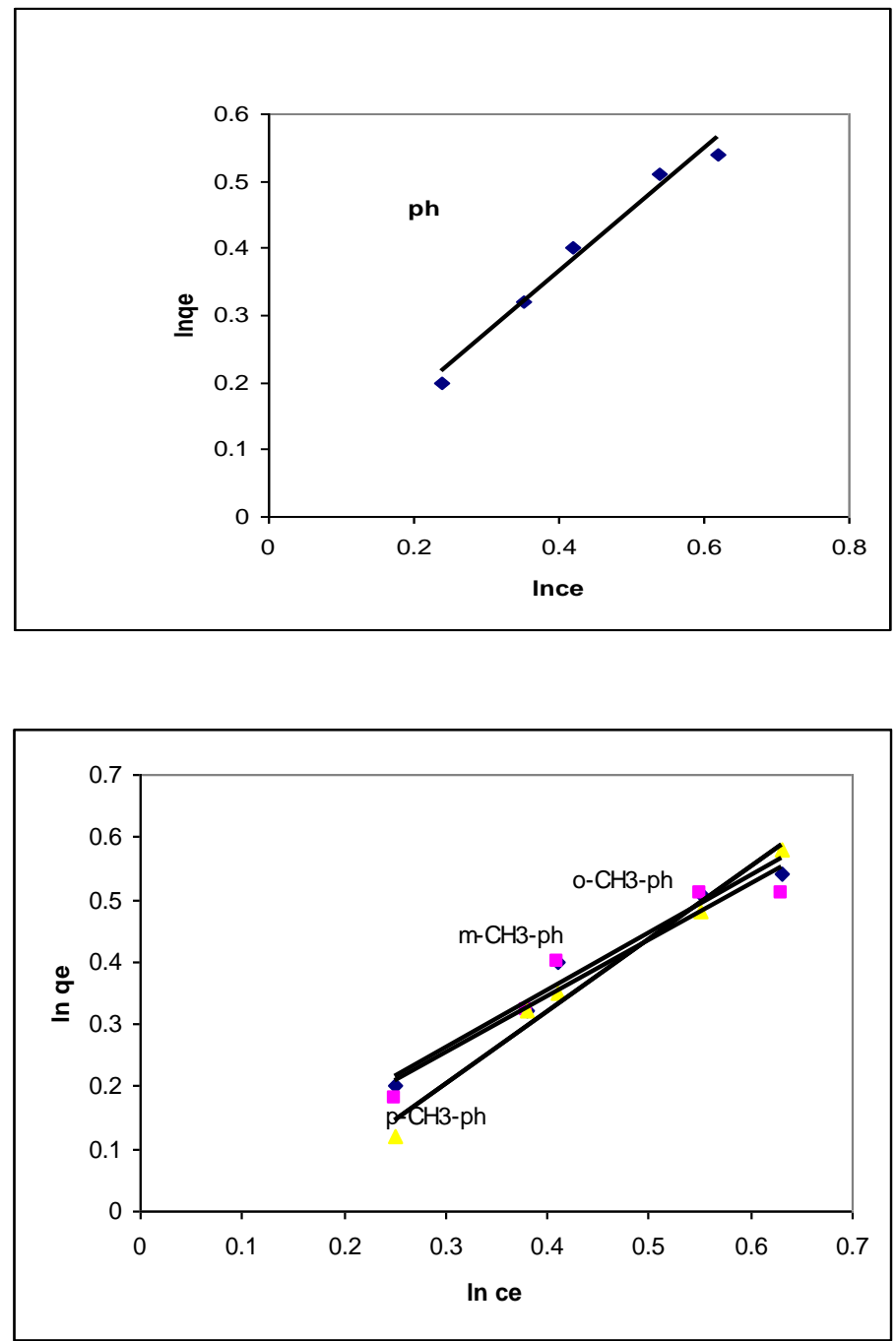
Safwan A. Al-Dbone
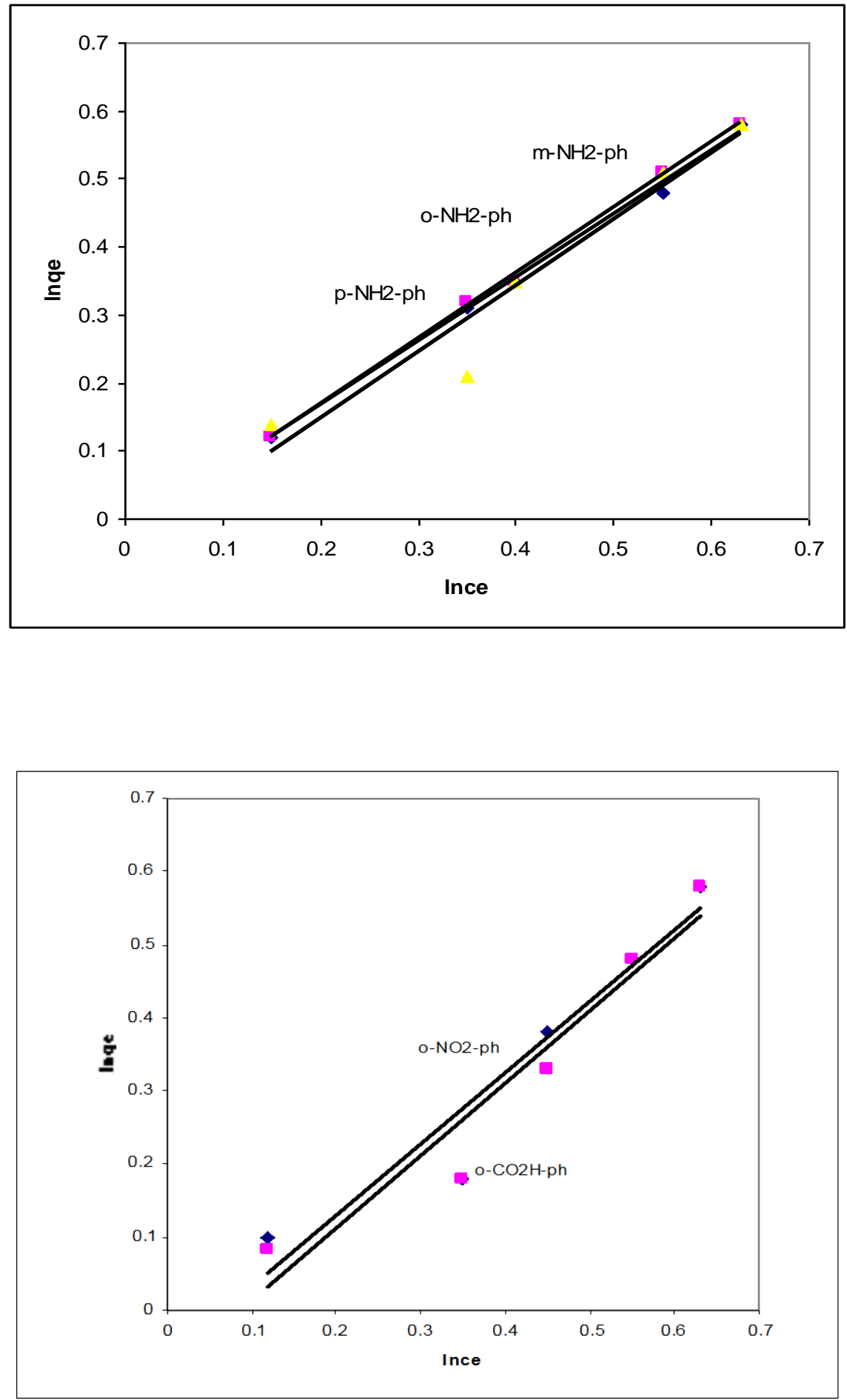


\section{Reference:}

1) Chipofya, V.H. and McConnachie, G. L., 2000, 1st WARFSA/Water Net Symposium: Sustainable Use of Water Resources, Maputo, 1-2 Nov.pp.1-4.

2) Mckay, Blair,G. H.S. and Gardner, J. R J. Appl. polyn. Sci., 1982, 27, 3043.

3) Zollinger, H. 1991, In Color Chemistry, Synthes, properties, and Application of Organic Dyes and pigments; $\mathrm{VCH}$ verlagsgesllschaft mbH, Weinbeim.

4) Knaebel, Kent. S. (2003), "Absorbent Selection" Adsorption Research, Inc., Dublin, Ohio, 43016, pp. 1-23.

5) Robert, M.C. 1989, "Grauu lar Activated Carbon, Design, operation and Costs", hew is "Publisher, pp.2-7.

6) EPA US., 2000, "Eastewater Technology Fact sheet, U.S. EPA. 823F- 00- 017, US. EPA Washington D.C.

7) Robert, C. H. 1996, Class Notes, CE 4104 Water and Waste Water Design, Virginia. Tech., pp.37, 48.

8) Haghsersht, S. Nouri, F. and L. Max, 2003, Abstract from Adsorption Science and Technology, Vol. 20, No.1.

9) Fariba, Amir, 2000, M. Sc. Thesis, Institute of water chemistry, Dresden Universty of Technology, Germany.

10) Banis, T. A. Al- D. G. Hela, T. M Sake llaried and Danis, T. G. 2000, "Removal of dyes from aqueous solutions by adsorption on mixture of fly ash and soil in batch and column technique" Global Nest, The Int. J., Vol.2 No. 3, pp. 237-241.

11) Tokat, A. Pala E. and Erkaya, H. 2000, "Removal of some reactive dyes from textile processing Wastewater using activated Carbon", Processing of the first Intentional conference on Environmental Research and Assessment, Bucharest, Romania, pp.114- 122.

12) Favere et al, T. 1998, "Adsorption of anionic dyes on the biopolymer chitin", J. Braz. Chem Soc., Vol.9 no.5, PP.435-440.

13) Al-Hyali A., Emad. Al-dubuni, Safwan A. and Ramadhan Omar M. T.2005, "Effect of Substituents Type on the Adsorption of Aromatic Carboxylic Acids and their Relation to Concentration, Temperature and pH", Raf. Jour. Sci., Vol. 16, No 3, Chemistry, Special Issue, pp. 68-79.

14) Hmdoon A. A, Aweed K.A and AL Dboone, S.A (2005) "preporation the activated carbon by chemical treatment and study effect of Gamma-ray on it ", J. Edu and Sci.,Vol.1, NO 2, PP12-19. 